\title{
AINDA EXISTEM CONSUMIDORES FIÉIS?
}

\author{
STILL EXIST LOYAL CONSUMERS?
}

Recebido - 02.11.10

Aceito - 05.03.11

\section{Lourenço Augusto Camargo Granato ${ }^{1}$ e Paula Fernanda Prado Pereira ${ }^{2}$}

\begin{abstract}
Resumo
O objetivo deste ensaio é analisar a influência que a evolução das mudanças econômicas e sociais exerceram sobre o comportamento do consumidor desde seus tempos mais remotos, passando por diversas fases, até a chegada ao cenário em que se vive hoje. Esta discussão acontecerá por meio da análise das diferentes fases de consumo que serão aqui apresentadas por ordem cronológica. O foco principal de cada fase é o consumidor e as mudanças que ocorreram em seu comportamento com o passar do tempo. Pôdese constatar que durante estas transições esse consumidor foi ganhando cada vez mais poder de decisão sobre suas escolhas e, a partir disso, mais poder no que se refere às tomadas de decisões estratégicas das organizações, que se encontram na constante busca da maior satisfação de seus consumidores.

A partir deste cenário e do modo como ocorrem as transações mercadológicas, somos conduzidos em direção ao seguinte questionamento: "Ainda existem consumidores fiéis?" ou em meio à grande diversidade de marcas, produtos e serviços a que se tem acesso atualmente, os consumidores apresentam comportamentos de compra mais "volúveis" e pouco fiéis em relação às marcas. Será que estes consumidores sofrem influências da realidade de um mundo consumista no qual vivem atualmente?

Palavras-chave: Comportamento. Consumidor. Economia. Mercado. Fidelidade.
\end{abstract}

1 Graduado em Administração de Empresas pela Universidade Mackenzie, com MBA Executivo em Marketing pela Escola Superior de Propaganda e Marketing (ESPM) e mestrando em Administração pela Pontifícia Universidade Católica de São Paulo (PUC-SP). Instituição: Pontifícia Universidade Católica de São Paulo (PUC-SP). Brasil. Email: gutogranato@uol.com.br

2 Graduada em Comunicação Social pela Escola Superior de Propaganda e Marketing (ESPM) e mestranda em Administração pela PUC-SP. Brasil. E-mail: paulafernandaprado@yahoo.com.br 


\begin{abstract}
The objective of this analysis is to verify the influence that the evolution of the economic and social changes had on the consumer behaviour since long time past, crossing several stages, until the arrival in the actual scenery. This discussion will happen through the analysis of the different consumption stages, here presented in chronologic order. The principal focus in each stage is the consumer and the changes that happened in his behaviour in due course. It can verify that during this transitions, he had been getting more and more decision power over his choices and, from this on, more power on the organizations strategic decisions, which are in a constant inquiry for their consumers satisfaction.

From this scenery and, in the way that happen the market transactions, we are taked through the following discussion: "Still Exist Loyal Consumers?" or in the middle of a large brands diversity, products and services with access nowadays, they have behaviours purchase more unstable, and not loyal with regard to the brands. Are these consumers influenced with a reality from a consuming world where they live nowadays?
\end{abstract}

Keywords: Behaviour. Consumer. Economy. Market. Loyalty.

\title{
CONSIDERAÇÕES INICIAIS
}

O consumo tem origem nos tempos mais remotos da humanidade, regidos essencialmente pelos processos de troca nos quais as pessoas trocavam bens, mas ainda não exerciam o que se conhece hoje como comércio.

Com o surgimento das primeiras transações, verificou-se um progresso econômico que tornou possível a troca dos excedentes da produção entre os membros da sociedade, gerando satisfação das necessidades para ambos os lados. Para essas transações tornarem-se cada vez mais recorrentes, surgiu a necessidade da criação de um mercado local (para a transação em moeda), como forma de valorização das mercadorias e efetuado por meio de intermediários. A partir de então, percebe-se a existência de três pilares essenciais para o processo de troca: o mercado, a moeda e as partes envolvidas, com início em civilizações passadas e que perduram até os dias atuais.

Esse mercado nunca foi fixo, pelo contrário, foi influenciado por unidades sociais que estão sempre em busca de novos valores e novos bens, no contexto de sua evolução. As inovações promoveram mudanças no comportamento social como um todo e, desde então, os detentores dos meios de produção visam atender às necessidades e desejos de cada grupo e unidades sociais. Com o passar do tempo, pôde-se observar a influência exercida pela sociedade nos diferentes setores da economia e nos mercados em geral; influência esta que foi ganhando cada vez mais força.

\section{O consumidor hoje}

De acordo com Kotler e Keller (2006, p.139),

\footnotetext{
os clientes de hoje possuem ferramentas para verificar os argumentos das empresas e buscar melhores alternativas. Acreditamos que avaliam qual oferta proporciona maior valor. Os clientes procuram sempre maximizar o valor, dentro dos limites impostos pelos custos envolvidos na procura e pelas limitações de conhecimento, mobilidade e renda. Eles formam uma expectativa de valor e agem com base nela. A probabilidade de satisfação e repetição da compra depende de a oferta atender ou não a essa expectativa de valor.
}

Rev. Adm. UFSM, Santa Maria, v. 4, n.1, p. 09-18, jan./abr. 2011 


\section{Por que o consumidor compra?}

Antigamente, os estudos tinham como principal foco a compreensão das transformações dos processos de troca dentro de um contexto essencialmente econômico e mercadológico. O estudo do comportamento do consumidor sob o ponto de vista mais humano e social foi alocado em segundo plano.

Com o passar do tempo, outras ciências, como a psicologia e a antropologia, passaram a inspirar e a exercer certa influência sobre os estudos que buscavam compreender o comportamento do consumidor e o modo como os mesmos se relacionam dentro da sociedade nos processos de troca.

Esses estudos vão além do conceito do indivíduo, para se estenderem também aos grupos sociais nos quais o mesmo encontra-se inserido. Influenciados por grupos e papéis sociais, os consumidores tomam suas decisões a partir de um conjunto de influências que incluem seu estilo de vida, seu nível cultural, suas relações com outros indivíduos, o nível de status que pretendem alcançar. Enfim, tudo que permeia seus relacionamentos dentro destes grupos sociais.

Os principais fatores de influência na decisão de compra são: motivação, personalidade e percepção do consumidor. Igualmente importantes são as variáveis essenciais no ato da compra: as Classes Sociais, as Variáveis Sociais, as Variáveis Econômicas e as Variáveis Culturais. Estas variáveis classificam o consumidor na sociedade.

O comportamento do consumidor é definido como o processo que se inicia antes da decisão de compra e se estende até o momento do pós-venda.

De acordo com Pachauri (2002), a evolução histórica deste conceito passa por diferentes perspectivas. São elas:

- Perspectiva racional: nas primeiras transações econômicas, simples atos de decisão de compra e reações pós-venda podem ser considerados como uma primeira versão do estudo do comportamento do consumidor. O comprador individual gasta parte de sua renda em bens que lhe proporcionam satisfação de suas necessidades;

- Perspectiva comportamental: em contraste com uma visão predominantemente econômica, que prioriza a importância dos processos mentais internos nas decisões do consumidor, a perspectiva comportamental enfatiza o papel exercido por fatores externos no processo de decisão, como, por exemplo, a influência de terceiros e o uso da propaganda, acompanhados de outras técnicas que também podem ser usadas para estimular, influenciar e controlar a resposta do consumidor;

- Perspectiva cognitiva: a perspectiva cognitiva visualiza o papel que o processamento das informações exerce sobre as decisões tomadas pelo consumidor. Identifica as pessoas como solucionadoras de problemas ao utilizar informações de fora para compreender seu ambiente. Consumidores passam por estágios de sentimento, pensamento e comportamento, fornecendo diversas respostas na medida em que são estimulados pelas diferentes ferramentas de marketing. Muitas decisões de compra tornam-se tão habituais que são realizadas com pouco ou nenhum esforço consciente. O nível de esforço comportamental existente em uma decisão é determinado pelo nível de diferenciação do produto pelo nível de envolvimento do consumidor com uma determinada categoria de produto, enquanto o risco percebido na aquisição de um produto (principalmente os caros) determina o grau de relevância para o consumidor;

- Perspectiva de personalidade: algumas compras possuem maior importância pessoal para certos consumidores e evidenciam elementos como preço, aumento da autoestima, sentimento de posse, e são considerados como reflexos da imagem almejada pelo consumidor. 
Embora os indivíduos não sejam lineares em todas as suas escolhas, pode-se realizar uma previsão das possíveis reações de grupos previamente definidos;

- Perspectiva motivacional: ferramentas de avaliação de personalidade que visam guiar ações de marketing, como, por exemplo, na segmentação de mercados baseados em perfis psicográficos, são uma maneira de se criar ações efetivas e mais bem-sucedidas. Pode-se até mesmo adaptar novas marcas para consumidores em busca da inovação. Em pesquisas psicográficas, por exemplo, pode-se conhecer quem compra, onde compra, com que frequência e quais suas razões de compra. Compreender o comportamento do consumidor leva a decisões estratégicas mais assertivas por parte das organizações;

- Perspectiva da influência situacional: a situação é definida por características de um indivíduo ou do bem por ele escolhido. A decisão de compra do consumidor pode ser motivada por impulso, por exemplo.

É importante para as organizações concentrar seus esforços na criação de produtos voltados para necessidades específicas de seu consumidor e do ambiente no qual vivem.

Os consumidores também podem ser estimulados no próprio ponto de venda, envolvidos por um odor ou um som agradável aos ouvidos. No contexto da comunicação, especialmente em propagandas, este recurso é bastante utilizado, fazendo-se uso de músicas e imagens capazes de provocar reações emocionais positivas sobre os consumidores.

$\mathrm{Na}$ ocasião de consumo, o humor e a condição psicológica do consumidor também possuem um papel importante no processo de decisão.

Atributos emocionais e racionais são determinantes nas escolhas do consumidor. É por isso que preço, promoção e distribuição devem ser estrategicamente definidos. Influenciados pela cultura e pelos grupos de referência do local em que vivem, os consumidores desenvolvem suas próprias características de compra. Cada consumidor é único em sua tomada de decisão, mas também pode sofrer influência daqueles que estão à sua volta.

\section{Uma breve evolução histórica e as fases do processo de compra}

O período mais marcante para a compreensão histórica das origens do consumo foi denominado Feudalismo, um tipo de organização econômica, social e política com base na terra, cujo início se deu na Europa Ocidental no período da Idade Média, estendendo-se até meados do século XV. Neste tipo de economia de subsistência, as produções agrícola e artesanal atendiam apenas ao consumo local e não eram produzidos bens para a venda. Portanto, ainda não existiam as chamadas trocas comerciais.

No entanto, o sistema feudal não pôde absorver o período seguinte de ampliação de mercado, que teve início a partir do século XVI, em que a criação de cidades, seguido pelo processo de urbanização e o aumento do consumo de produtos urbanos levou os senhores feudais a substituírem as obrigações servis por dinheiro e, até mesmo, a expulsarem os servos de suas terras, passando a utilizar mão de obra excedente e mais barata.

Uma vez nas cidades, o servo, livre por ter comprado a sua liberdade ou por ter fugido, passa a ser o artesão dentro das corporações, tornando-se o produtor independente que atenderia ao mercado local. É a partir deste período que surge espaço para a denominada Revolução Industrial. 


\section{A 1a Fase do processo de compra: o período da Revolução In-
dustrial}

A Revolução Industrial foi um período de profundas transformações socioeconômicas ocorridas na Europa a partir do ano de 1750, no qual se observou a saída relativa de um sistema feudal e agrário para um sistema capitalista. Com o fim dos feudos, as cidades passaram a se desenvolver e surgiram os primeiros estados nacionais, que colocaram os reis no topo da pirâmide social. Este período de nacionalização teve início em Portugal e propagou-se para a Inglaterra, França e Espanha, conduzindo ao período das grandes descobertas e das grandes navegações, abrindo portas para o surgimento de colônias e, por consequência, de novos mercados a serem explorados.

Tratou-se da consolidação de um novo período histórico, que possibilitou o surgimento do capitalismo industrial. O modo de produção capitalista, definido por meio das forças produtivas e das relações sociais de produção, baseou-se em bens de consumo (tendo como pioneira a indústria têxtil), o que levou a melhorias nos meios de transporte (terrestres e marítimos), ao desenvolvimento da metalurgia, do motor a vapor e do carvão como energia.

Nesse período, surge a cultura de consumo, possibilitada pela distribuição de produtos a preços mais acessíveis, conduzindo à expansão e ao crescimento da denominada classe média. Os valores, os desejos e os comportamentos foram alterados no campo social, refletindo-se em aspectos como a cidadania e a religião, por exemplo. Esta evolução do comportamento do consumidor revelou atitudes associadas à aquisição, à posse, ao consumo e à disposição de bens e serviços. Assim, os consumidores passaram a moldar constantemente suas intenções e desejos, sempre visando satisfazer a necessidade por aquilo que buscavam.

Com a expansão da população urbana, inicia-se um aumento da oferta e da demanda por produtos e serviços voltados para este indivíduo ávido para consumir.

Passada a Revolução Industrial, abriu-se caminho para o surgimento das marcas. Com o aumento da demanda, os fabricantes viram-se obrigados a identificar os produtos e serviços por eles produzidos e oferecidos, criando rótulos e embalagens diferenciadas e comunicando a existência de suas marcas para seus consumidores.

Em meio a esse cenário, o consumidor passa a ser o principal personagem do processo de compra, pois é ele quem escolhe as marcas que irá consumir. Em meio a um crescente número de ofertas, ele começa a concentrar o poder de escolha em suas mãos.

Desde essa época, os profissionais da comunicação já podiam se esforçar para compreender e, assim, influenciar a decisão de compra dos consumidores, identificando se o apelo deveria ser mais emocional ou racional.

\section{A 2 a fase dos processos de compra: o surgimento das grandes marcas e a abertura econômica (Décadas de 1940 e 1950)}

Depois da Segunda Guerra Mundial, os pesquisadores de marketing perceberam a necessidade de estudar com maior ênfase o comportamento do consumidor e sua tomada de decisão no processo de compra, porque, passado o período de escassez promovido pela guerra, a economia voltou com uma força ainda maior.

A concorrência entre as organizações começou a aumentar, dando início a um período mais crítico para as organizações. É nesse cenário que começaram a surgir as grandes corporações. 
As escolas de gerenciamento do pensamento de marketing também surgiram logo após a Segunda Guerra Mundial, em um período de expressivo crescimento econômico, com introdução de novos produtos e gerando conceitos como o dos quatro P's do marketing, mix de marketing, diferenciação de produto e multisegmentação.

Nesse momento, começou-se a caminhar em direção a um mercado cada vez mais produtivo, influenciado pelo rápido crescimento econômico e financeiro, surgindo a necessidade de novas práticas de negócios, em detrimento das novas formas de produção. Deu-se início à produção em larga escala, que originou o Fordismo, por exemplo, um processo de produção em massa e de larga escala, visando atender às necessidades dos consumidores dessa época.

O consumidor passou a valorizar cada vez mais as marcas, vistas como um indicador de garantia e qualidade e cuja imagem começou a ser aproveitada na elaboração de estratégias segmentadas.

Os elementos que compõem os 4P's, passaram a compor as estratégias das organizações, sendo que cada uma toma suas decisões fazendo uso desses quatro elementos e, conforme seu modelo de negócio, dá ênfase para um ou mais dos 4 P's.

De acordo com Kotler (2001), cada um dos 4 P's abrange os seguintes itens:

- Produto: variedade de produtos, qualidade, design, características, nome de marca, embalagem, tamanhos, serviços, garantias e devoluções;

- Preço: preço de lista, descontos, concessões, prazos de pagamento e condições de financiamento;

- Praça: canais, cobertura, variedades, locais, estoque e transporte;

- Promoção: promoção de vendas, publicidade, força de vendas, relações públicas e marketing direto.

É importante lembrar-se de que, embora este tenha sido um período de plena expansão econômica, o sortimento de produtos que se tinha na época, em número, não chega à metade do número de marcas que se tem nos dias de hoje.

A seguir, uma breve exemplificação de como foi este período, por meio do caso da empresa "The Coca-Cola Company".

\section{O caso Coca-Cola}

Um exemplo de marca bem-sucedida e que teve o ápice de seu crescimento nesse período é a "The Coca-Cola Company", que desenvolveu como uma de suas principais estratégias, acompanhar os soldados dos EUA no período da guerra, a um preço de US\$0,05 para todo combatente norte-americano onde quer que ele estivesse, em qualquer parte do mundo, não importando o quanto isto poderia custar à empresa.

Durante a guerra, os europeus experimentaram a bebida e, quando a paz voltou a reinar, a Coca-Cola já tinha muitos negócios fora de seu território. Essa visão da organização em distribuir seus produtos de modo a distribuí-los sempre ao alcance das pessoas, é uma estratégia que existe até os dias de hoje e que, com toda a certeza, já faz parte da essência dessa organização. Entre as décadas de 1940 e 1960, o número de países com operação de envasamento praticamente dobrou. O período pós-guerra nos Estados Unidos é marcado pelo otimismo e pela prosperidade não somente para a Coca-Cola, mas também para muitas outras empresas que se expandiram e que continuam sólidas até os dias atuais. 
Em uma estratégia de expansão internacional, é necessária uma análise das semelhanças entre os mercados, oferecendo-se produtos e estratégias facilmente adaptáveis. No entanto, cada caso tem suas características particulares e é por isso que deve ser analisado com muito critério, pois muitas organizações já tiveram grandes prejuízos por escolherem mal suas estratégias.

Algumas marcas globais tiveram um expressivo crescimento e outras não, apresentando diferentes resultados de participação de mercado devido à sua capacidade de adaptação em quesitos como a comunicação e campanhas de divulgação nos mais diferentes mercados, com culturas e comportamentos específicos.

Ao identificar quem são seus consumidores, as organizações podem estabelecer estratégias de marketing com maior vantagem competitiva frente a seus concorrentes. O correto posicionamento de um produto é um fator chave para o sucesso da organização.

\section{3 a fase: os mercados globais e o aumento da diversidade de mar- cas (década de 1990)}

Essa fase se constitui um dos principais momentos históricos de expansão vivido pelas organizações, pois elas passaram a atender necessidades que iam além de seu mercado local, para conquistar novas fronteiras.

Este cenário é favorecido pela facilidade nos transportes (marítimo, aéreo e ferroviário) e pelos diferentes acordos de livre comércio que começaram a tomar forma nas mais diversas partes do mundo. A população mundial em constante crescimento possibilitou o aumento da demanda por novos produtos e serviços.

Nesse momento, os consumidores detêm mais poder em suas mãos e passam a ter acesso a uma maior diversidade de marcas, com diferentes atributos e benefícios, como maior qualidade e menor preço, por exemplo. O consumidor começa a expandir seus horizontes e as organizações iniciam uma luta mais feroz, na medida em que competem, agora, em todos os aspectos, pois o nome de suas marcas já não é suficiente, não pode ser considerado o único sinônimo de qualidade frente à concorrência.

A abertura de mercado em muitos países também possibilitou a ampliação da diversidade de marcas disponíveis ao consumidor (um bom exemplo deste momento foi a abertura do mercado automobilístico vivido pelo Brasil em meados de 1992, quando o presidente em exercício, Fernando Collor, abriu o mercado brasileiro para novos entrantes, marcas que até então não se tinha acesso).

A partir do surgimento e desenvolvimento de mercados globais, diferentes valores culturais tiveram de ser levados em consideração nas estratégias das organizações. Os hábitos de compra, assim como o estilo de vida, os valores, as crenças e as atitudes começaram a ser estudados.

Ao ingressar em novos mercados, as organizações devem ter como principal objetivo direcionar suas atividades em busca da satisfação das necessidades e dos desejos daquele mercado em questão. Isto pode ser considerado um fator crítico de sucesso uma vez estando em novas fronteiras.

Consumidores mudam o tempo todo, não apenas em mercados conhecidos, mas também em novos mercados. Como seus desejos nem sempre são previsíveis, os chamados "caso de sucesso" não devem ser aplicados em todos os mercados nos quais as organizações estão situadas, pois podem apresentar diferentes resultados, muitas vezes negativos e inesperados, na 
medida em que estes mercados são compostos por diferentes consumidores, de diferentes sociedades e culturas.

É importante ressaltar que as estratégias globais das organizações multinacionais devem ser flexíveis, de modo a se adaptarem facilmente aos novos consumidores.

Um importante aspecto que surgiu no fim da década de 1990 foram os avanços tecnológicos que passaram a crescer cada vez mais a partir desse período. Um exemplo a ser citado é o caso da China e da Índia, os maiores polos tecnológicos dos dias atuais, e cujo crescimento econômico serve de exemplo para outros países. São mercados do futuro, com potencial de produção global, mão de obra barata e que, com o passar do tempo, alcançaram o título de principais produtores mundiais.

\section{4a fase: a customização dos bens em função das necessidades do consumidor (ano 2000)}

Na era contemporânea, os hábitos dos consumidores tornaram-se índices estratégicos na tomada de decisão das organizações, pois suas ações servem como base para relatórios de pesquisas de mercado e dados estatísticos.

Sistemas de banco de dados, como o Customer Relationship Management (CRM), gerenciam as relações entre as empresas e o consumidor, identificando o perfil do consumidor, a frequência de compra e os hábitos de consumo; enfim, são sistemas que conhecem o consumidor de maneira profunda. Não se pode afirmar que são capazes de prever cada passo do consumidor, pois muitas características subjetivas que acontecem no processo de compra são inerentes ao seres humanos e, por isso, não podem ser armazenadas apenas por um software.

Conhecer o seu consumidor é um diferencial competitivo, e as organizações têm valorizado este tipo de conhecimento, pois os mercados estão cada vez mais saturados. É notório que aquele que conhece bem seu mercado e seu consumidor toma decisões mais acertadas. Com base no conhecimento do público-alvo, as organizações estão mais seguras para criar ofertas personalizadas e produtos que possam ser customizados pelos consumidores.

Um ponto importante a ser ressaltado no cenário em que se vive atualmente é que o fácil acesso às mais variadas marcas de produtos e serviços faz com que o consumidor procure bens que Ihe confiram uma diferenciação cada vez maior. Já não lhe interessa possuir aquilo que todos possuem, e o foco do interesse passa a ser o diferente, o exclusivo.

Um bom exemplo a ser citado é o mercado de luxo, que tem crescido cada vez mais nos últimos anos. Marcas como Dolce \& Gabbana, que há até pouco tempo oferecia apenas artigos de moda, como roupas e sapatos, hoje em dia, em parceria com a Motorola, oferece a seus consumidores um modelo de celular exclusivo de cor dourada, adornado por cristais de uma outra marca, a Svarovski.

Em grande parte dos mercados atuais, o consumidor contemporâneo tende a ser facilmente envolvido por atributos emocionais no ato de compra. Esse tipo de influência se reflete também nos meios de comunicação e, por consequência disso, em grande parte das propagandas a que se assiste hoje. Compras influenciadas por atributos racionais, como o preço, ocorrem em mercados específicos, mas que também sofrem variações de acordo com o perfil do consumidor em questão.

Pode-se considerar que a era pós-moderna trouxe junto consigo um vazio, e o consumidor, movido pelas influências que estão à sua volta, tende a querer preencher este vazio com compras, consumindo cada vez mais. 
É importante ressaltar que fidelizar novos consumidores é, na maior parte das vezes, mais difícil e tem um retorno menor quando comparado à fidelização de consumidores antigos, cujo relacionamento já se encontra em evolução e manutenção constante.

O relacionamento surge como ponto essencial no estabelecimento e manutenção das relações entre consumidores e organizações. Em um futuro próximo, a construção e o estreitamento desses laços assumirá um importante papel na conquista de uma posição sólida no mercado.

O grande compromisso para o avanço do conhecimento do comportamento do consumidor consiste no desenvolvimento de teorias que sejam aplicáveis ao mercado, e espera-se que essa tendência continue para exploração de muitos outros tópicos.

Para as organizações, o principal desafio que se vive atualmente é a necessidade de renovação e diferenciação para a sobrevivência e o sucesso de seus produtos e serviços na "Era do Descartável", isto porque as evoluções tecnológicas, além de trazerem muitas facilidades para o mundo moderno, também aumentaram os desafios para as organizações, pois as mudanças que acontecem rapidamente levam à criação de novos produtos o tempo todo.

\section{CONCLUSÃO}

O estudo do comportamento do consumidor evoluiu como um diferente campo de conhecimento a partir da década de 1960 e vem ganhando força até o presente momento. Muitos pesquisadores basearam seus estudos em ciências, como psicologia social, sociologia e antropologia, e estão sempre em busca da implementação de novas técnicas e perspectivas para melhor compreender a natureza do comportamento do consumidor. Este, que se influencia pelo estilo de vida, valores, culturas e grupos de referência.

A pesquisa que se faz antes de se oferecer determinado produto ou serviço ao consumidor é essencial para que se evitem catástrofes de vendas, pois, dessa maneira, pode-se estimar qual a real demanda por aquele bem ou serviço. A partir de então, com um preço adequado, uma distribuição capilarizada nos mercados específicos e uma comunicação eficiente, a organização terá maiores chances de obter sucesso naquele mercado em questão.

O marketing apresenta-se como um campo de conhecimento pelo qual se interpretam os desejos e as necessidades do consumidor, traduzindo isto em uma transação efetiva de bens e serviços que possam satisfazer o indivíduo.

É importante destacar que os indivíduos estão situados em diferentes classes sociais, compostas por pessoas que compartilham os mesmos valores, têm interesses comuns e apresentam comportamentos similares. Em geral, os estilos de vida são semelhantes, ocasionados por rendas similares. Diferentes grupos de referência também podem influenciar o comportamento do indivíduo, até mesmo porque o mesmo exerce diferentes papéis na sociedade em que vive.

O indivíduo busca cada vez mais uma diferenciação frente à sociedade, como maneira de expor sua individualidade, perante uma sociedade cada vez mais massificada. É por isso que hoje, frente a tantas marcas de produtos e serviços, há uma tendência cada vez maior para a criação de produtos exclusivos, personalizados ou até mesmo customizados pelo próprio consumidor.

Grupos de referência são importantes por exercerem um poder muito grande sobre as decisões dos indivíduos, pois, muitas vezes, as pessoas se espelham em "ícones" ao escolherem determinado produto ou serviço. Isto é bastante utilizado na comunicação, quando marcas escolhem celebridades para endossar seus produtos em campanhas publicitárias. 
O principal desafio de hoje para o estudo do comportamento do consumidor é identificar quais são as verdadeiras influências sobre a tomada de decisão do consumidor, porque, frente a tantas opções, esse mesmo consumidor vem sendo cada vez mais imprevisível em sua tomada de decisão no ambiente de consumo.

Conforme visto no presente artigo, o consumidor sofre os mais diversos tipos de influências, podendo agir de maneira mais racional ou emocional, dependendo do tipo de produto ou serviço que venha escolher em sua tomada de decisão. Por isso, torna-se cada vez mais difícil para as organizações preverem como os consumidores irão agir nos diferentes mercados e se serão fiéis a seus produtos ou serviços.

\section{Referências bibliográficas}

KOTLER, Philip; KELLER, Kevin. Administração de marketing. 12. ed. São Paulo: Pearson Prentice Hall, 2006.
PACHAURI, Moneesha. Consumer behavior: a literature review. The Marketing Review, p. 319$355,2002$. 